\title{
Ultrasonic Properties of Hexagonal Closed Packed Metals
}

\author{
Alok Kumar Gupta ${ }^{1}$, Archana Gupta ${ }^{2}$, Sudhanshu Tripathi ${ }^{3, *}$, Vyoma Bhalla ${ }^{4}$, Devraj Singh ${ }^{4}$ \\ ${ }^{1}$ Academic Department, National Institute of Open Schooling, NOIDA-201309, India \\ ${ }^{2}$ Department of Biochemistry, University of Lucknow, Lucknow-226007, India \\ ${ }^{3}$ Department of Instrumentation and Control Engineering, Amity School of Engineering and Technology, New Delhi-110061, India \\ ${ }^{4}$ Department of Applied Physics, Amity School of Engineering and Technology, New Delhi-110061, India \\ *Corresponding Author: tripathisudhanshu@gmail.com
}

Copyright (C) 2013 Horizon Research Publishing All rights reserved.

\begin{abstract}
This work is focused on three types of ultrasonic velocities $\left(\mathrm{V}_{1}, \mathrm{~V}_{2}\right.$ and $\left.\mathrm{V}_{3}\right)$ in $\mathrm{Mg}$ and $\mathrm{Cd}$ hcp metals. These are determined using the SOEC and TOEC at room temperature. Ultrasonic waves were supposed to be propagated along different directions with the crystal axis (z-axis). Finally ultrasonic attenuation in $\mathrm{Mg}$ and $\mathrm{Cd}$ are evaluated at room temperature utilizing the SOEC and TOEC of the materials. Average wave velocity is highest at $\theta=55^{\circ}$ along $\mathrm{z}$-axis in these materials. The contributions of the elastic constants, thermal conductivity, thermal energy density, ultrasonic velocity and acoustic coupling constant to the total attenuation are studied.
\end{abstract}

Keywords Ultrasonic Velocity, Acoustic Coupling Constant, Ultrasonic Attenuation

\section{Introduction}

Magnesium and Cadmium are hexagonal close packed structured metal. As with other related rare earth metals, these are malleable, ductile and lustrous silvery white metals. Magnesium chloride is present in sea water. It is widely distributed in the vegetable kingdom being present in chlorophyll, the green coloured pigment in leaves. Magnesium is not tarnished in dry air. In contact with wet air, a thin layer of oxide is coated on the metal surface. In flash light photography, $\mathrm{Mg}$ wire burns with dazzling light in an atmosphere of oxygen. The light is rich in ultraviolet radiations. Magnesium is used as an alloying agent in producing Magnalium, which is extensively used in the construction of aeroplanes, motors, and balance beams light instruments. Being highly electropositive in nature, it is used for sacrificial protection of iron pipelines, piers and ships against corrosion. It is also used as deoxidiser for removing last traces of oxygen from copper, steel, etc.

Cadmium is white, lustrous, but tarnishable metal. Their structure deviates only slightly from perfect hcp. Cadmium is remarkably volatile for heavy metals. The elements have relatively low abundance in nature (of the order $10^{-6}$ of earths crust for $\mathrm{Cd}$.), but have long be know because this is easily obtained from their ores. Cadmium is very electro positive and react readily with nonoxidizing acids releasing $\mathrm{H}_{2}$ and giving the divalent ions. The element $\mathrm{Cd}$. from many alloys. Cadmium is mostly found isomorphously replacing zinc in zinc minerals. It is also used the low efficiency of nuclear reactor.

There is a plenty (abundant) of literature on behaviour of elastic constant and thermal properties of these metals [1-7], but the studies on ultrasonic propagating behaviour in these materials are not reported in literature. The aim of present chapter is to establish the theory of for determination of ultrasonic attenuation, ultrasonic velocity, thermal relaxation time and other related parameters like non-linearity constants (acoustic coupling constants) in the materials at $300 \mathrm{~K}$.

In the present paper three types of ultrasonic velocities $\left(\mathrm{V}_{1}\right.$, $\mathrm{V}_{2}$ and $\mathrm{V}_{3}$ ) in $\mathrm{Mg}$ and $\mathrm{Cd}$ are determined using the SOEC and TOEC at room temperature. Ultrasonic waves were supposed to be propagated along different directions with the crystal axis (z-axis). Finally ultrasonic attenuation in $\mathrm{Mg}$ and $\mathrm{Cd}$ are evaluated at room temperature utilizing the SOEC and TOEC of the materials. Acoustic coupling constants (non-linearity constants) and thermal relaxation time are determined for the determination of ultrasonic attenuation.

\section{Theory: Theoretical Description is Categorized into Two Parts}

\subsection{Ultrasonic Velocity In Hep Crystal}

There are three types of ultrasonic velocities in hcp crystals as one longitudinal and two shear wave velocities, which are given by the following expressions [8-11].

$$
V_{1}^{2}=\left\{C_{33} \cos ^{2} \theta+C_{11} \sin ^{2} \theta+C_{44}+\left\{\left[C_{11} \sin ^{2} \theta-C_{33} \cos ^{2} \theta+C_{44}\left(\cos ^{2} \theta-\sin ^{2} \theta\right)\right]^{2}\right.\right.
$$




$$
\begin{gathered}
\left.\left.+4 \cos ^{2} \theta \sin ^{2} \theta\left(C_{13}+C_{44}\right)^{2}\right\}^{1 / 2}\right\} / 2 \rho \\
V_{2}^{2}=\left\{C_{33} \cos ^{2} \theta+C_{11} \sin ^{2} \theta+C_{44}-\left\{\left[C_{11} \sin ^{2} \theta-C_{33} \cos ^{2} \theta+C_{44}\left(\cos ^{2} \theta-\sin ^{2} \theta\right)\right]^{2}\right.\right. \\
\left.\left.+4 \cos ^{2} \theta \sin ^{2} \theta\left(C_{13}+C_{44}\right)^{2}\right\}^{1 / 2}\right\} / 2 \rho \\
V_{3}^{2}=\left\{C_{44} \cos ^{2} \theta+C_{66} \sin ^{2} \theta\right\} / \rho
\end{gathered}
$$

Where $\mathrm{V}_{1}, \mathrm{~V}_{2}$ and $\mathrm{V}_{3}$ are the longitudinal, quasi-shear and shear wave velocities. The $\rho$ and $\theta$ are the density of the material and angle with the unique axis (z-axis) of the crystal. $\mathrm{C}_{11}, \mathrm{C}_{13}, \mathrm{C}_{33}, \mathrm{C}_{44}$ and $\mathrm{C}_{66}$ are the second order elastic constants (SOEC) of the material.

The room temperature properties of the crystals are commonly characterized by Debye average velocity. This is determined as the mean (Debye) sound velocity $(\overline{\mathrm{V}})$, which is calculated from the initial slopes of the three acoustical branches [12-13].

$$
\overline{\mathrm{V}}=\left(\frac{1}{3} \sum_{\mathrm{i}=1}^{3} \int \frac{1}{\mathrm{~V}_{\mathrm{i}}^{3}} \frac{\mathrm{d} \Omega}{4 \pi}\right)^{-1 / 3}
$$

The integration is over all directions and the summation is over the three acoustic branches $\left(\mathrm{V}_{\mathrm{i}}\right)$.

\subsection{Ultrasonic Attenuation}

According to Mason [14], the two dominant processes that will give rise to appreciable ultrasonic attenuation in hexagonal structured materials at high temperatures are phonon-phonon interaction also known as Akhieser loss and that due to thermo-elastic attenuation. The ultrasonic attenuation coefficient $(\alpha)_{\mathrm{Akh}}$ (Akhieser type loss) due to phonon-phonon interaction mechanism is given by following expression [14-17].

$$
(\alpha)_{\mathrm{Akh}}=\omega^{2} \Delta \mathrm{C} \tau / 2 \rho \mathrm{V}^{3}\left(1+\omega^{2} \tau^{2}\right)
$$

where $\omega$ is angular frequency of the wave and $\mathrm{V}$ is the velocity of ultrasonic wave (longitudinal and shear). $\tau$ is the thermal relaxation time whose expression is as:

$$
\tau=\tau_{\mathrm{S}}=\tau_{\mathrm{L}} / 2=3 \mathrm{~K} / \mathrm{C}_{\mathrm{V}} \overline{\mathrm{V}}^{2}
$$

Here $\tau_{L}$ and $\tau_{S}$ are the thermal relaxation time for longitudinal and shear wave. $\mathrm{K}$ and $\mathrm{C}_{\mathrm{V}}$ are the thermal conductivity and specific heat per unit volume of the material. $\Delta \mathrm{C}$ is change in elastic modulus caused by strain and is given by:

$$
\Delta \mathrm{C}=3 \mathrm{E}_{0}<\left(\gamma_{\mathrm{i}}^{\mathrm{j}}\right)^{2}>-<\gamma_{\mathrm{i}}^{\mathrm{j}}>^{2} \mathrm{C}_{\mathrm{V}} \mathrm{T}=\mathrm{E}_{0} \mathrm{D} / 3
$$

Where $\mathrm{E}_{0}$ is thermal energy density and $\gamma_{\mathrm{i}}^{\mathrm{j}}$ Grüneisen number: $i, j$ are the mode and direction of propagation.

The propagation of longitudinal ultrasonic wave creates compression and rarefaction throughout the lattice. The rarefied regions are colder than that of the compressed region. Thus there is flow of heat between these two regions. Hence thermo-elastic loss $(\alpha)_{\text {th }}$ occurs and is given by [16-17].

$$
(\alpha)_{\mathrm{th}}=\omega^{2}<\gamma_{\mathrm{i}}^{\mathrm{j}}>^{2} \mathrm{KT} / 2 \rho \mathrm{V}_{1}^{5}
$$

The calculations have been carried out both manually and a computer program in MATLAB, which is based on formulae given in paper. The program has been confirmed and verified with previous calculations.

\section{Results and Discussion}

The values of second and third order elastic constants for $\mathrm{Mg}$ and $\mathrm{Cd}$ are taken from literature [6-7] and are presented in the Table 1 . The value of density $(\rho)$ and thermal conductivity $\mathrm{K}$ at $300 \mathrm{~K}$ are taken from the physical constant table. The value of specific heat per unit volume $\left(\mathrm{C}_{\mathrm{V}}\right)$ and thermal energy density $\left(\mathrm{E}_{0}\right)$ are evaluated using physical constant table and Debye temperature [18]. The values of K, $\rho, \mathrm{C}_{\mathrm{V}}$ and $\mathrm{E}_{0}$ are presented in Table2.

Table 1. SOEC and TOEC in $10^{10} \mathrm{~N} / \mathrm{m}^{2}$ for $\mathrm{Mg}$ and $\mathrm{Cd}$ at $300 \mathrm{~K}$.

\begin{tabular}{|c|c|c|}
\hline SOEC/TOEC & $\mathrm{Mg}$ & $\mathrm{Cd}$ \\
\hline $\mathrm{C}_{11}$ & 5.943 & 1.158 \\
\hline $\mathrm{C}_{12}$ & 2.560 & 3.975 \\
\hline $\mathrm{C}_{13}$ & 2.140 & 4.06 \\
\hline $\mathrm{C}_{33}$ & 6.146 & 5.14 \\
\hline $\mathrm{C}_{44}$ & 1.642 & 2.039 \\
\hline $\mathrm{C}_{66}$ & 1.691 & 3.801 \\
\hline $\mathrm{C}_{111}$ & -64.300 & -2.448 \\
\hline $\mathrm{C}_{112}$ & -17.900 & -7.91 \\
\hline $\mathrm{C}_{113}$ & -6.300 & -1.71 \\
\hline $\mathrm{C}_{123}$ & -4.700 & -7.3 \\
\hline $\mathrm{C}_{133}$ & -17.100 & -2.0 \\
\hline $\mathrm{C}_{144}$ & -4.500 & -6.8 \\
\hline $\mathrm{C}_{155}$ & -6.500 & -1.76 \\
\hline $\mathrm{C}_{222}$ & -73.700 & -2.92 \\
\hline $\mathrm{C}_{333}$ & -63.200 & -6.67 \\
\hline $\mathrm{C}_{344}$ & -17.100 & -2.0 \\
\hline & & \\
\hline
\end{tabular}


Table 2. Thermal conductivity $\mathrm{K}\left(\mathrm{Wm}^{-1} \mathrm{~K}^{-1}\right)$, density $\rho\left(10^{3} \mathrm{Kgm}^{-3}\right)$, specific heat per unit Vol. $\mathrm{C}_{\mathrm{V}}\left(10^{6} \mathrm{Jm}^{-3} \mathrm{~K}^{-1}\right)$, thermal energy density $\mathrm{E}_{0}\left(10^{8}\right.$ $\mathrm{Jm}^{-3}$ ), for $\mathrm{Mg}$ and $\mathrm{Cd}$ at $300 \mathrm{~K}$.

\begin{tabular}{|c|c|c|}
\hline Physical constants & $\mathrm{Mg}$ & $\mathrm{Cd}$ \\
\hline $\mathrm{K}$ & 156.00 & 970 \\
\hline$\rho$ & 1.740 & 3.65 \\
\hline $\mathrm{C}_{\mathrm{V}}$ & 1.641 & 1.881 \\
\hline $\mathrm{E}_{0}$ & 3.155 & 4.416 \\
\hline
\end{tabular}

The three ultrasonic velocities $\mathrm{V}_{1}, \mathrm{~V}_{2}$ and $\mathrm{V}_{3}$ are

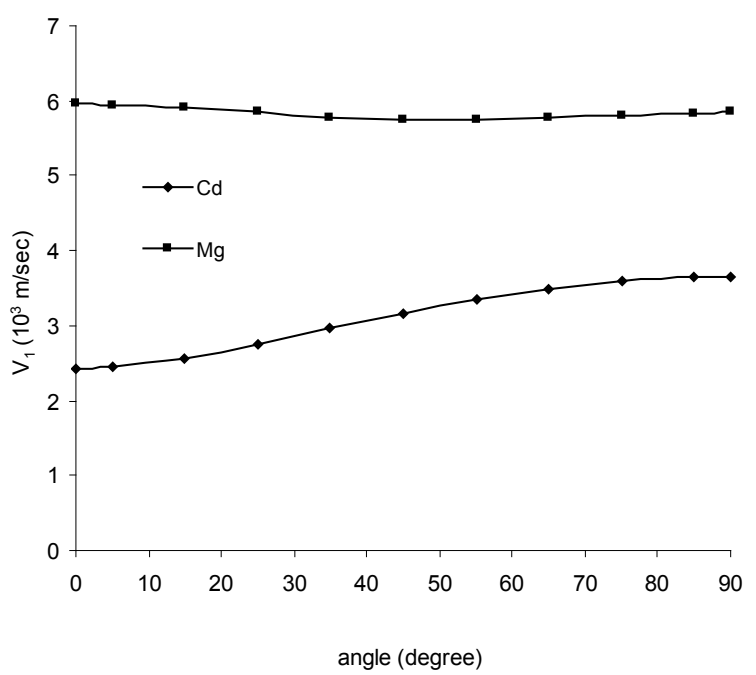

Figure 1. Longitudinal velocity $\left(\mathrm{V}_{1}\right) \mathrm{Vs}$. angle with z-axis

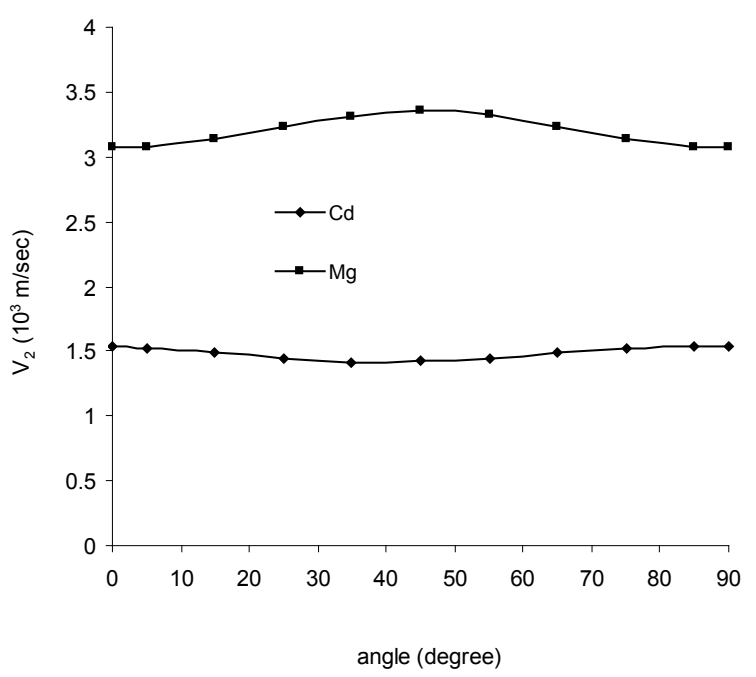

Figure 2. Quasi shear velocity $\left(\mathrm{V}_{2}\right) \mathrm{Vs}$. angle with z-axis calculated using the second order elastic constants and the Eqs. (1)-(3) at $300 \mathrm{~K}$ and different angles with the unique axis (z-axis) of the crystal. The obtained values of velocities are presented in Table 3 and Figures. 1-3. The thermal relaxation time $(\tau)$ is calculated at different angles with unique axis of the crystal. The present values of $\tau$ and $\bar{V}$ are given in Table 4. The angle dependency of thermal relaxation time is shown in Figure 4. The Grüneisen numbers are calculated by the expressions given by Nandanpawar et al. [19] at $300 \mathrm{~K}$ taking $\theta=0^{0}$. The Grüneisen numbers and acoustic coupling constants are presented in Table 5 .

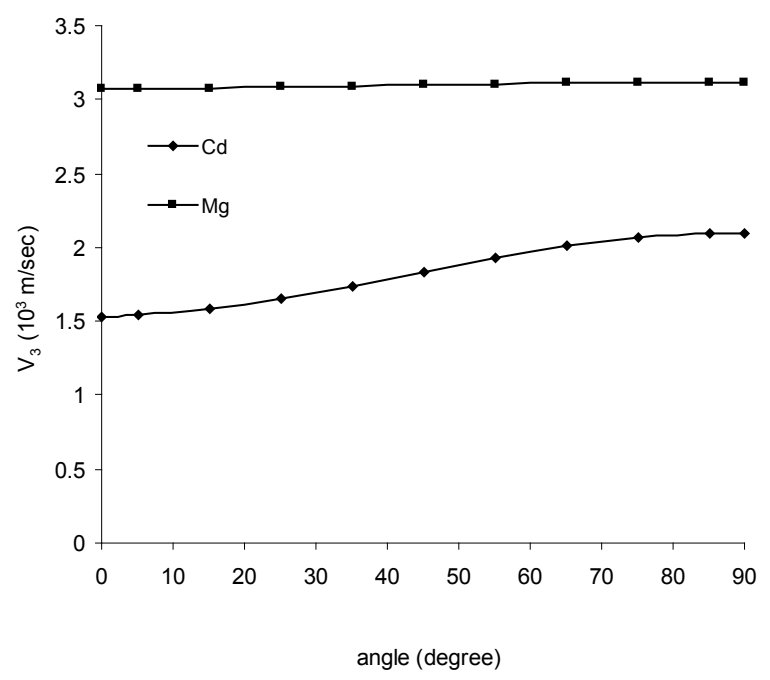

Figure 3. Shear velocity $\left(\mathrm{V}_{3}\right) \mathrm{Vs}$. angle with z-axis

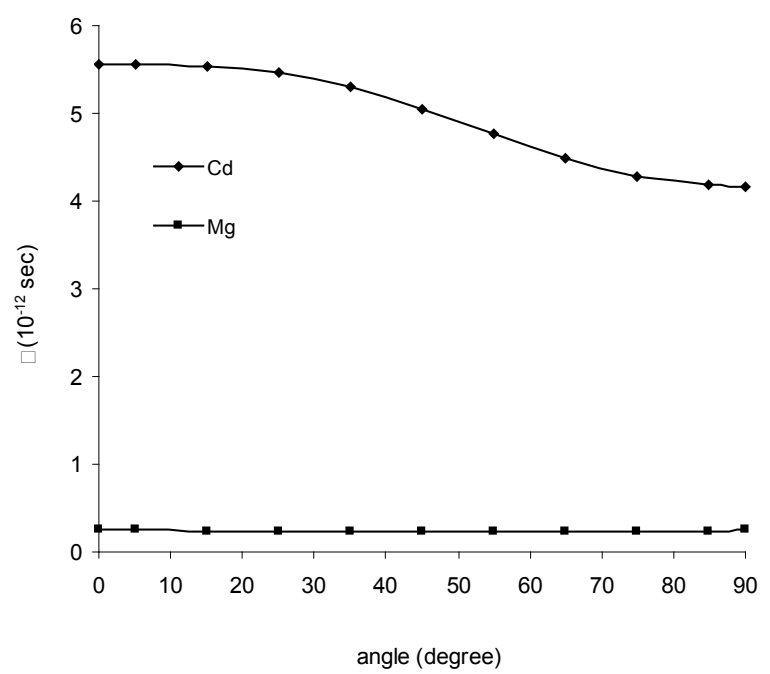

Figure 4. Thermal relaxation time $(\tau)$ Vs. angle with z-axis 
Table 3. Velocity $\left(V_{1}, V_{2}\right.$, and $\left.V_{3}\right)$ at different angles $(\theta)$ from $Z$-axis for $\mathrm{Mg}$ and $\mathrm{Cd}$ at $3000 \mathrm{~K}$.

\begin{tabular}{|c|c|c|c|c|c|c|}
\hline $\begin{array}{c}\text { Metal } \\
\rightarrow\end{array}$ & $\mathrm{Mg}$ & $\mathrm{Cd}$ & $\mathrm{Mg}$ & $\mathrm{Cd}$ & $\mathrm{Mg}$ & $\mathrm{Cd}$ \\
\hline$\theta$ & $\mathrm{V}_{1}$ & $\mathrm{~V}_{1}$ & $\mathrm{~V}_{2}$ & $\mathrm{~V}_{2}$ & $\mathrm{~V}_{3}$ & $\mathrm{~V}_{3}$ \\
\hline 0 & 5.952 & 2.437 & 3.072 & 1.535 & 3.072 & 1.535 \\
\hline 5 & 5.947 & 2.453 & 3.080 & 1.528 & 3.072 & 1.540 \\
\hline 15 & 5.910 & 2.567 & 3.139 & 1.485 & 3.075 & 1.579 \\
\hline 25 & 5.847 & 2.749 & 3.232 & 1.438 & 3.080 & 1.649 \\
\hline 35 & 5.783 & 2.957 & 3.317 & 1.416 & 3.087 & 1.740 \\
\hline 45 & 5.743 & 3.162 & 3.353 & 1.422 & 3.095 & 1.837 \\
\hline 55 & 5.743 & 3.345 & 3.321 & 1.450 & 3.103 & 1.930 \\
\hline 65 & 5.774 & 3.494 & 3.237 & 1.485 & 3.110 & 2.008 \\
\hline 75 & 5.814 & 3.598 & 3.142 & 1.515 & 3.115 & 2.063 \\
\hline 85 & 5.841 & 3.652 & 3.080 & 1.533 & 3.118 & 2.093 \\
\hline 90 & 5.844 & 3.658 & 3.072 & 1.535 & 3.118 & 2.096 \\
\hline
\end{tabular}

Table 4. Debye average elocity $\left(10^{3} \mathrm{~m} / \mathrm{sec}\right)$ and relaxation time $\tau_{\text {th }}\left(10^{-12} \mathrm{~s}\right)$ at different angles $(\theta)$ from $\mathrm{Z}$-axis for $\mathrm{Mg}$ and $\mathrm{Cd}$ at $300 \mathrm{~K}$.

\begin{tabular}{|c|c|c|c|c|}
\hline Metal $\rightarrow$ & \multicolumn{2}{|c|}{$\mathrm{Mg}$} & \multicolumn{2}{c|}{$\mathrm{Cd}$} \\
\hline$\theta$ & $\overline{\mathrm{V}}$ & $\tau_{\text {th }}$ & $\overline{\mathrm{V}}$ & $\tau_{\text {th }}$ \\
\hline 0 & 3.396 & 0.2473 & 1.669 & 5.549 \\
\hline 5 & 3.400 & 0.2467 & 1.669 & 5.547 \\
\hline 15 & 3.430 & 0.2424 & 1.672 & 5.527 \\
\hline 25 & 3.474 & 0.2363 & 1.683 & 5.459 \\
\hline 35 & 3.513 & 0.2310 & 1.708 & 5.031 \\
\hline 45 & 3.532 & 0.2287 & 1.749 & 5.052 \\
\hline 55 & 3.523 & 0.2298 & 1.802 & 4.758 \\
\hline 65 & 3.490 & 0.2342 & 1.856 & 4.488 \\
\hline 75 & 3.448 & 0.2399 & 1.899 & 4.289 \\
\hline 85 & 3.419 & 0.2440 & 1.922 & 4.186 \\
\hline 90 & 3.415 & 0.2445 & 1.925 & 4.173 \\
\hline
\end{tabular}

A perusal of Figure 1 shows that a minimum of longitudinal velocity $\left(\mathrm{V}_{1}\right)$ is found at $55^{\circ}$ with the unique axis for $\mathrm{Mg}$, it decreases with angle while velocity increases for $\mathrm{Cd}$. Figure 2 shows that quasi shear velocity $\left(\mathrm{V}_{2}\right)$ has maximum value for $\mathrm{Mg}$ and minimum for $\mathrm{Cd}$ at $45^{\circ}$. Figure 3 shows that the pure shear velocity $\left(\mathrm{V}_{3}\right)$ slightly increases for $\mathrm{Mg}$ and $\mathrm{Cd}$ with the angle. All the anomalous behaviour in three type of velocity in these metals is due to anomalous values of the second order elastic constants (SOEC), which is the direct consequence of the crystal anisotropy. Figures 1-3 demonstrate that $\mathrm{V}_{1}$ has minimum value for $\mathrm{Mg}$ at $55^{\circ}$ while increasing value of $\mathrm{Cd}, \mathrm{V}_{2}$ is maximum for $\mathrm{Mg}$ and minimum for $\mathrm{Cd}$ at $45^{\circ}$ and $\mathrm{V}_{3}$ is maximum for $\mathrm{Mg}$ and $\mathrm{Cd}$ both at $90^{\circ}$.

Figure 4 shows that if ultrasonic wave is supposed to propagate along different angles with the unique axis then the time for reestablishment of thermal phonons equilibrium decreases from $0^{0}-35^{\circ}$ and shows a minimum at $45^{\circ}$ and increases from $55^{\circ}-90^{\circ}$ for $\mathrm{Mg}$ but in case of $\mathrm{Cd}$ it decreases from $0^{\circ}-90^{\circ}$ and shows a maximum at $0^{\circ}$ and minimum $90^{\circ}$. Debye average velocity is affecting factor for the anomalous nature of relaxation time. The reestablishment of thermal phonons (relaxation time) is maximum when ultrasonic wave is propagated along $\theta=0^{0}$ with the unique axis of the crystal.

Table 5. Average Gruneisen number $<\gamma_{i}^{j}>\mathrm{L}$, square of average Gruneisen number $<\left(\gamma_{i}^{j}\right)^{2}>\mathrm{L}$ for longitudinal wave, average square Gruneisen number $\left\langle\left(\gamma_{i}^{j}\right)^{2}\right\rangle_{L}$ and $\left\langle\left(\gamma_{i}^{j}\right)^{2}\right\rangle_{S}$ for longitudinal and shear wave and non-linearity constants $\mathrm{D}_{\mathrm{L}}, \mathrm{D}_{\mathrm{S}}$ for longitudinal and shear wave along $\mathrm{Z}$-axis for $\mathrm{Mg}$ and $\mathrm{Cd}$ at $300^{\circ} \mathrm{K}$.

\begin{tabular}{|c|c|c|c|c|c|}
\hline $\begin{array}{c}\text { Parameter } \\
\mathrm{s}\end{array}$ & $\mathrm{Mg}$ & $\mathrm{Cd}$ & $\begin{array}{c}\mathrm{Ti} \\
{[21]}\end{array}$ & $\begin{array}{c}\mathrm{Zr} \\
{[21]}\end{array}$ & $\begin{array}{c}\mathrm{Hf} \\
{[21]}\end{array}$ \\
\hline$\left\langle\gamma_{\mathrm{i}}^{\mathrm{j}}\right\rangle_{\mathrm{L}}$ & -1.0125 & 82.769 & & & \\
\hline$\left\langle\gamma_{\mathrm{i}}^{\mathrm{j}}\right\rangle_{\mathrm{L}}^{2}$ & 1.0251 & 2.771 & & & \\
\hline$\left\langle\left(\gamma_{\mathrm{i}}^{\mathrm{j}}\right)^{2}\right\rangle_{\mathrm{L}}$ & 22.2209 & 6.850 & & & \\
\hline$\left\langle\left(\gamma_{\mathrm{i}}^{\mathrm{j}}\right)^{2}\right\rangle_{\mathrm{S}}$ & 0.1299 & 1.653 & & & \\
\hline $\mathrm{D}_{\mathrm{L}}$ & 195.1897 & 2.468 & 55.965 & 56.314 & 56.521 \\
\hline $\mathrm{D}_{\mathrm{S}}$ & 1.1694 & 1.487 & 1.406 & 1.249 & 1.418 \\
\hline
\end{tabular}

The ultrasonic attenuation coefficient $\left(\alpha / \mathrm{f}^{2}\right)_{\mathrm{Akh}}$. for longitudinal and shear wave are calculated at $300 \mathrm{~K}$ taking $\theta=0^{0}$ Thermoelastic loss $\left(\alpha / \mathrm{f}^{2}\right)_{\text {th. }}$ is also calculated at $300 \mathrm{~K}$ taking $\theta=0^{0}$. The values of $\left(\alpha / \mathrm{f}^{2}\right)_{\text {Akh }}$ and $\left(\alpha / \mathrm{f}^{2}\right)_{\text {th }}$ are presented in Table 6.

Table 6. Ultrasonic attenuation coefficient $\left(\alpha / \mathrm{f}^{2}\right)_{\mathrm{Akh} \text {. }}$ in $10^{-14} \mathrm{NpS}^{2} \mathrm{~m}^{-1}$ and thermoelastic attenuation coefficient $\left(\alpha / \mathrm{f}^{2}\right)_{\text {th }}$ in $10^{-16} \mathrm{NpS}^{2} \mathrm{~m}^{-1}$ for longitudinal and shear waves along $\mathrm{Z}$-axis $\left(\theta=0^{\circ}\right)$ for $\mathrm{Mg}$ and $\mathrm{Cd}$ at $300^{\circ} \mathrm{K}$ and $10 \mathrm{MHz}$.

\begin{tabular}{|c|c|c|c|}
\hline Metal & $\left(\alpha / \mathrm{f}^{2}\right)_{\text {Akh.long. }}$ & $\left(\alpha / \mathrm{f}^{2}\right)_{\text {Akh.shear }}$ & $\left(\alpha / \mathrm{f}^{2}\right)_{\text {th }}$ \\
\hline $\mathrm{Mg}$ & 10.915 & 23.80 & 7280.0 \\
\hline $\mathrm{Cd}$ & 0.0127 & 0.0016 & 0.0006 \\
\hline
\end{tabular}

Grüneisen parameter plays a significant role in study of thermoelastic properties of materials. It is used to describe physical properties of the materials. The SOEC and TOEC are used to obtain Grüneisen numbers expressions as given in literature[19]. The average Grüneisen parameter of $\mathrm{Cd}$ is more than $\mathrm{Mg}$ as shown in Table 5. So we can say that $\mathrm{Cd}$ is 
stronger candidate than $\mathrm{Mg}$ for thermoelastic purpose [20]. The acoustic coupling constant (D) is measure of acoustic energy converted into thermal enrgy under relaxation process. A comparison for $\mathrm{D}$ has been made in Table 5 with hcp lanthanide metals [21]. The obtained results are more or less similar to them.

Here, a theoretical calculation is done for ultrasonic attenuation in hep metals $\mathrm{Mg}$ and $\mathrm{Cd}$. The above discussion implies that the characteristic values of $\mathrm{V}_{1}, \mathrm{~V}_{2}$ and $\mathrm{V}_{3}$ of $\mathrm{Mg}$ metal are correlated with the second order elastic constants. The orientation dependent relaxation time is mainly affected by Debye average velocity. The ultrasonic attenuation for longitudinal wave is predominantly affected by thermal energy density and mass density of the metal and the ultrasonic attenuation for shear wave is predominantly affected by the shear wave velocity and relaxation time. The longitudinal wave velocity is the dominating property for the thermoelastic loss. By these informations, the anisotropic behaviour and characteristic features of this material can be understood and the results obtained by present theoretical approach are informative for the understanding of basic properties of this hep metal Mg.

\section{Conclusion}

On the basis of above discussion, we conclude following points:

1. Average ultrasonic velocity increases from $\theta=0^{\circ}$ to $55^{\circ}$, then it decreases from $\theta=55^{\circ}$ to $90^{\circ}$ in these metals. Hence it is maximum at $55^{\circ}$ along z-axis.

2. Thermal relaxation time $(\tau)$ decreases first from $0^{\circ}-45^{\circ}$, then it increases from $45^{\circ}-90^{\circ}$ (in case of $\mathrm{Mg}$ ) while it decreases continuously in case of cd like a relaxation $\tau=\tau_{0} \exp (-\lambda / \mathrm{T})$.

3. Acoustic coupling constant (D) of Mg for longitudinal wave is more, while it is less for cd.

4. Ultrasonic attenuation due to phonon-phonon interaction mechanism is predominant over themoelastic loss.

Obtained results of present investigation can be used for further investigation and industrial applications.

\section{REFERENCES}

[1] H. F. Bezdek, R. E. Schmunk, L. Finegold, Lattice dynamics of zirconium, Physica Status Solidi b, Vol. 42, No. 1, 275-280, 1970.

[2] E. S. Fisher, M. H. Manghnani, Effects of Changes in Vol.and $\mathrm{c} / \mathrm{a}$ ratio on pressure derivatives of the elasic moduli of H.C.P, $\mathrm{Ti}$ and $\mathrm{Zr}$, Journal of Physics and Chemistry of Solids, Vol. 32, No. 3, 657-667,1971.

[3] E. S. Fisher, M. H. Manghnani, R. Kikuta, Hydrostatic pressure derivatives of the single crystal elastic moduli of Gd, Dy and Er, Journal of Physics and Chemistry of Solids, Vol.
34,No. 4, 687-703,1973.

[4] S. Sindhu, C. S. Menon, Higher order elastic constants and generalised gruneisen parameters of elastic waves and low temperature thermal expansion of dysprosium, Journal of Physics and Chemistry of Solids,, Vol. 58,No. 12,2001-2006,1997.

[5] R. R. Rao, C. S. Menon, Dispersion relations and lattice thermal expansion of dysprosium, Journal of Physics and Chemistry of Solids,, Vol. 34,No. 11, 1879-1886,1973.

[6] R. R. Rao, C. S. Menon, Lattice dynamics, third order elastic constants and thermal expansion of gadolinium, Journal of Physics and Chemistry of Solids, Vol. 35,No. 3, 425-432,1974.

[7] R. Srinivasan, R. Ramji Rao, Anharmonic properties of the hexagonal metals, magnesium, zinc and beryllium-I. Lattice dynamics and third order elastic constants, Journal of Physics and Chemistry of Solids, Vol. 32, No. 8, 1769-1788, 1971.

[8] G.A. Alers, J.R. Neighbours, The elastic constants of zinc between $4.2^{\circ}$ and $670^{\circ} \mathrm{K}$, Journal of Physics and Chemistry of Solids Vol. 7, No. 1, 58-64, 1958.

[9] M. Rosen, H. Klimker, Low-Temperature Elasticity and Magneto-Elasticity of Dysprosium Single Crystals, Physical Review B, Vol. 1, No. 9, 3748-3756, 1970.

[10] D.K.Pandey, D.Singh, P.K.Yadawa, Ultrasonic study of osmium and ruthenium,Platinum Metals Review,Vol. 53,No. 2,91-97,2009.

[11] D.K.Pandey, D.Singh, R.R.Yadav,Ultrasonic wave propagation in IIIrd group nitrides,Applied Acoustics, Vol.68,No.7,766-777,2007

[12] C. Oligschleger, R. O. Jones, S. M. Reimann, H. R. Schober, Model interatomic potential for simulations in selenium, Physical Review B, Vol. 53, No. 10, 6165-6173, 1996.

[13] D.Singh, S.Kaushik, S.Tripathi, V.Bhalla, A.K Gupta,Temperature dependent elastic and ultrasonic properties of berkelium mononictides, Arabian Journal for Science and Engineering - (In Press).

[14] W.P.Mason, Physical Acoustics, Vol. III B,Academic Press,New York, 1965.

[15] V.Bhalla, R.Kumar, C.Tripathy, D.Singh, Mechanical and thermal properties of praseodymium monopnictides: an ultrasonic study,International Journal of Modern Physics B,Vol. 27, No.22, 1350116(28 pages), 2013.

[16] A.K.Gupta, A.Gupta, D.Singh, S.Tripathi, Sensitivity of Nanostructured iron metal on ultrasonic properties, Open Journal of Metal,vol 1,No.2, 34-40,2011.

[17] D.Singh, S.tripathi, D.K.Pandey, A.K.Gupta, D.K.Singh,J.Kumar,Ultrasonic wave propagatioin semimetallic single crystal,Modern Physics letters B, Vol.25, No.31, 2377-2390, 2011.

[18] D. E. Gray (Ed.), AIP Handbook, Mc-Graw Hill Book Co. Inc., New York, 1965.

[19] M. Nandanpawar, S. Rajagopalan, Grüneisen numbers in hexagonal crystals Journal of the Acoustical Society of America, Vol. 71, No. 6, 1469-1472, 1982.

[20] S.Kaushik, D.Singh, G.Mishra, Elastic and ultrasonic 
properties of $\mathrm{XBi}(\mathrm{X}=\mathrm{B}, \mathrm{Cm}$ and $\mathrm{U})$, Asian Journal of Chemistry, Vol.24, No.12, 5655-5658, 2012.

[21] P.K.Yadawa, D.K. Pandey, d.Singh,R.R.Yadav,G.Mishra,Co mputations of ultrasonic parameters of lanthanide metals Ti,Zr and Hf,Turkish Journal of Physics, Vol.34, No.1, 23-31, 2010 . 